\title{
Rosario López GREGoRIS (ed.), Mujer y violencia en el teatro antiguo. Arquetipos de Grecia y Roma, Madrid, Los Libros de la Catarata, 2020, 144 páginas, ISBN 978-84-1352-152-7
}

\author{
María TeReSA Muñoz García de ITURROSPE \\ Universidad del País Vasco / Euskal Herriko Unibertsitatea \\ ORCID: https://orcid.org/0000-0003-1155-022X \\ maite.munoz@ehu.eus
}

DOI: https://doi.org/10.24197/mrfc.34.2021.243-247

L

a manifestación escénica reitera y con ello reinterpreta a lo largo de los siglos actitudes de violencia y agresión contra mujeres, inevitablemente a través de estereotipos. Si nos remontamos al teatro grecorromano, entre estos paradigmas sin duda se piensa en primer lugar en grandes malvadas trágicas, como Clitemnestra y Medea, mujeres obstinadas que encarnan la violencia especialmente monstruosa, pero también en las sacrificadas Ifigenia y Políxena, e incluso en cómicas como Lisístrata y Praxágora, las cuales, mediante la inversión de roles, actúan como hombres. Sin embargo, ni unas ni otras son nunca presentadas como víctimas de violencia “común” y más realmente dolorosa y cercana, eje del volumen objeto de esta reseña.

Con buen criterio, y a la vista del resultado siempre riguroso y meticuloso, quienes aquí escriben han decidido apartarse de la tónica más habitual de estudios anteriores, que han tendido a centrarse casi en exclusividad en las razones y en las condiciones socio-políticas que sustentaban la violencia pública y doméstica. Así, y de forma muy equilibrada, reviven como peculiares y sufridas víctimas, trágicas y cómicas mujeres a menudo esclavas, pero también ciudadanas y hasta soberanas, que encarnan bien diversos personajes, casi siempre marginados, arquetipos mudos que se expresan paradójicamente a través de diálogos ajenos y de situaciones relatadas desde la distancia; cuando ellas intervienen es de forma escueta, pensada para el efecto inmediato en un público que asume como ejemplar y/o divertido ese encadenamiento intencionado de humillaciones, insultos, amenazas y golpes.

En esta línea, Rosario LÓPEZ GREGORIS (pp. 7-11) ofrece un eficaz prólogo, que sirve para presentar los objetivos de la publicación, que adelanta lo que une y distingue sus partes, pero también confirma que también se ha tenido presente ese necesario y fructífero viaje de doble sentido entre pasado y actualidad, todo ello con la asimismo oportuna mirada inclusiva.

Los cinco capítulos siguientes logran mantener un conseguido tono de ensayo de divulgación de calidad, con apartados iniciales contextualizadores que no se desvían de la cuestión (riesgo habitual cuando de estos temas se trata) y bibliografía 
generosa, selecta y actualizada al final de cada uno. Se logra así mostrar y comentar mediante claves diversas múltiples aspectos concretos que enriquecen una cuestión mayor de interés social general y, es evidente, académico. El canon clásico es bien conocido, pero los textos que aquí se presentan -en traducciones siempre cuidadas, con breves anotaciones de índole léxica cuando así se requiere- no lo son tanto. El índice onomástico final es una buena prueba de este despliegue textual, si bien podría haberse dividido en indices auctorum (et locorum) para ordenar y poner mejor en evidencia la cantidad y la variedad de registros aportados.

Es muy loable otro aspecto que parece haber sido decisión común: se ha dejado hablar a los autores cómicos y, en menos número, trágicos, aunque sea sobre la fuerza ejercida sobre otras personas y ello no los haga "simpáticos". Incluso me atrevo a suponer que la claridad de la redacción de los cinco trabajos está alentada como respuesta a lo que tanto sucede en otros trabajos académicos, que a menudo suavizan en sus traducciones y comentarios esa violencia y agresividad que no esconden los textos originales. Es esta una cuestión que sigue sorprendiendo, a la vista de los reparos que aún subsisten a la hora de traducir (por no comprender su alcance) términos clave como, por ejemplo, raptum; valga como ejemplo de denuncia de esta práctica el trabajo de Zola Marie Packman (1993), "Call it Rape: A Motif in Roman Comedy and Its Suppression in English-speaking Publications”, Helios 20, 42-55.

La primera de las contribuciones, a cargo de Begoña ORTEGA VILLARO ("La violencia contra la mujer en la comedia ateniense: de Aristófanes a Menandro”, pp. 13-48), resulta ser un perfecto ejemplo de equilibrio. Se trata de un bien fundamentado estudio sobre la cambiante forma a la hora de poner de manifiesto la múltiple presentación de argumentos dramáticos sobre la mujer que sufre violencia, tanto simbólica como sobre todo física en la comedia griega. Sigue sorprendiendo la cantidad de agresiones silenciadas y siempre contadas desde la distancia temporal y espacial por otras mujeres que ejercen de confidentes o de narradoras de estos hechos tiempo después, cuando hay criaturas fruto de esas violaciones. De hecho, se nos confirma que estas, presentadas como un temor para las mujeres en Aristófanes, pasan a ser parte habitual de la trama en Menandro, que incluye ya agresiones a ciudadanas, casi sin excepción por parte de jóvenes borrachos y apasionados, a menudo en el transcurso de festivales religiosos y de noche. Estas comedias (de nuevo en particular las menandreas) ya apuntan los fundamentales argumentos que alimentarán durante tantos siglos la literatura misógina "festiva" y evidentemente también la "seria": la culpa implícita de las mujeres, maleducadas por otras y amantes en exceso del vino y hasta del sexo (justamente lo que a ellos les sirve de atenuante ante el público).

El segundo capítulo ("Mujer y violencia en la comedia plautina. Una historia corriente”, pp. 49-71) lo dedica Rosario LÓPEZ GREGORIS a la real cotidianidad del maltrato y de la vejación contra mujeres de toda condición que muestran numerosos episodios cómicos, que alargan y nutren sus tramas con escenas protagonizadas por gente corriente que, sea esclava o sea libre -como muy acertadamente se reivindica 
en un apartado que titula "Enfoque"-, no tiene voz. La autora parte de unas nociones previas sobre el amor y el discurso de los personajes plautinos en un contexto patriarcal, lo que da paso, de nuevo, a una sucesión de breves pero esclarecedores subapartados dedicados a la violencia física que sufren más esclavas y ancianas, que distingue entre la violencia sexual -que sufren esclavas y mujeres anónimas en burdeles, pero también hijas obligadas a veces por sus propias madres a dedicarse a la prostitución- y la violencia extrafamiliar vehiculada, como en la comedia de Menandro, a través escenas de violación de ciudadanas ("bajo la influencia del vino y el ardor de la juventud”, "por culpa del vino”), con un embarazo y una boda como consecuencia que parecen pretender aligerar el primer uso de la fuerza. El golpe de realidad asombra cuando se aparta del formulismo literario y aflora el sentimiento, a menudo de rebelión. A este respecto, el contrapunto que ofrece el género epigráfico, que es literatura de calle por antonomasia, habría sido un buen complemento, hasta para confirmar tanto el capital aspecto de la contención verbal exigida a ellas como algunos efectos sociales y emocionales; contrastan, como ejemplo, el aislado pero demoledor testimonio del epitafio de Lyon dedicado por su hermano y por sus hijos a una mujer asesinada por su marido -IVLIA MAIANA, MANV MARITI CRVDELISSIM(I) INTERFECTA (CIL XIII 2182)- con tantos textos, muchos de ellos carmina epigraphica, en que se ensalza y promueve la concordia, con expresiones como sine ulla querella.

A esta agresividad verbal en la comedia plautina dedica Luis UNCETA GÓMEZ un capítulo ("La violencia verbal contra las mujeres en las comedias de Plauto: ¿una forma de humor?, pp. 72-97) que sirve además como perfecta introducción a los estudios sobre la importancia del análisis tanto de la cortesía como de la descortesía lingüística. Se parte de una sucinta pero eficacísima presentación de los rasgos particulares de la comedia palliata, entre ellos la delineación de las relaciones sociales a través de unos personajes muy prototípicos ("lo que convierte a estas obras en un corpus especialmente adecuado para los estudios de sociolingüística y pragmática histórica", que permiten además "recuperar ciertas informaciones acerca del contexto extralingüístico no explicitados en los parlamentos”, p. 74). Es muy interesante -en un momento en que se trata de nuevo sobre la inevitable relación violencia-esclavitud- que se subraye que son las conversaciones entre esclavos las que muestran una acritud mayor. Tampoco faltan los insultos dentro del matrimonio, con escenas que sugieren que el esposo puede ser también víctima (Cas. 228 ss.); sólo que tenemos que recordar que un poco antes la misma Cleóstrata ha confesado los malos modos domésticos de su marido (uir me habet pessumis despicatam modis, ibid. 189). Agradecemos otra vez la comparación eficaz con los usos modernos tan diversos que cotidianamente se difunden en cine, sitcoms, debates políticos, programas del corazón, la inclusión de "nuevas" manifestaciones, como la slapstick 
comedy ${ }^{1}$, pero también, cuando llega el momento de reconocer las más crudas expresiones de agresión, la triste comparación con la actualidad. Así, contrasta la visión amable de la película en clave de comedia Pretty Woman del director Garry Marshall con los planteamientos sin contemplaciones que identifican a las esclavas sexuales de Camboya con las de las comedias plautinas, apoyados en una excelente reflexión de Christopher W. Marshall (en su estudio, quizá por la coincidencia no incluido en la bibliografía, "Sex slaves in New Comedy", en B. Akrigg y R. Tordoff (eds.), Slaves and Slavery in Ancient Greek Comic Drama, Cambridge, CUP, 2013, 173-196). Por lo demás, desfilan amenazas e insultos, más habituales lógicamente que las contadas escenas de palizas contra mujeres en escena, de nuevo entre los estratos más maltratados de la sociedad romana: quien se enfrenta a la prostituta es un esclavo, como en la reveladora escena que el profesor Unceta califica de hecho como "violencia de clase" (Truc. 256-279, p. 81). Son escenas y usos verbales que sin duda influyeron en escenas "cómicas” posteriores en otros géneros, como aquella con un airadísimo Trimalción que golpea a su esposa Fortunata (ii!!) en respuesta a los insultos provocados por los celos, primero golpeándola y arrojándole un cáliz, para luego ofenderla verbalmente con profusión (PETRON. 74), episodio que suscitaría la risa fácil y, al tiempo, evidenciaría, en el caso de Petronio, su desprecio por los nuevos ricos; y como la que protagoniza ese matemático del que escribe Agustín de Hipona que golpea a su mujer por hablar petulantius, relacionarse con otras personas y asomarse demasiado a la ventana, acabando por reaccionar como un personaje plautino, ágil tricolon incluido: nonne arripit, verberat et dat disciplinam in domo sua? (AVG. in psalm. 140, 9).

Sigue una contribución con título muy sugestivo ("Recuerdos del bien y del mal. Guerra y violación en la tragedia ática”, pp. 98-112), en la que Marta GONZÁLEZ GONZÁLEZ aborda con sensibilidad y rigor esta cuestión inevitable y por desgracia tan reconocible hoy y siempre cuando de mujer y guerra se trata. La autora sitúa de forma central un momento trágico de Siete contra Tebas en que Esquilo da voz a un coro de aterradas mujeres de toda edad y condición, apartándose de cualquier justificación de la violencia y sin acudir al argumento de la culpa femenina como detonante de los conflictos bélicos, tan frecuente en géneros tan diversos como la épica, la tragedia y la historia. De nuevo aplaudimos el vínculo con nuestro tiempo y agradecemos especialmente su apartado novedoso, dedicado a los usos terapéuticos de la tragedia, ayer y hoy, que aquí se centran en la presentación de dos proyectos bien diversos: el que gira en torno a una re-versión de las Troyanas de Eurípides, en forma de trece refugiadas como Queens of Syria con la dirección de escena de Zoe Lafferty, con posterior documental a cargo de Yasmin Fedda; y el proyecto de Bryan Doerries y su Theatre of War, que nace en Brooklyn para ofrecer esta terapia textual a traumatizados veteranos, atentos a la lectura de fragmentos de Áyax y Filoctetes de

\footnotetext{
${ }^{1}$ Antecedente con mujeres violentas contra hombres: Hiponacte, en el fragmento 22 (23 D), presenta una escena en la que una mujer agrede presuntamente a su rival, “dejándole <ella> sin nariz y sin mocos":

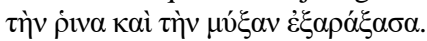


Sófocles. Unas y otros ya no son "lectores comunes" privilegiados, pero siguen recurriendo al poder sanador (y reivindicativo) de la lectura de los trágicos en tiempos de guerra como Virginia Woolf cuando rescata a Antígona en Tres Guineas.

Finalmente cierra el libro Dido, el personaje trágico que en Roma se convierte en modelo excepcional, a veces positivo, casi siempre con un elemento pérfido, pese a su infelicidad (o precisamente por ella) y sin duda también por su condición de extranjera. A los complejos episodios virgilianos que perfilan su retrato trágico dedica un detallado comentario filológico Rosario CORTÉs TOVAR ("Infelix Dido, reina de Cartago: víctima trágica del sistema patriarcal”, pp. 113-138), en el que se subrayan los elementos trágicos que inducen a un personaje poderoso (dux femina, regina) a convertirse en víctima por su condición de mujer y cuyo suicidio, alentado en parte por la violencia verbal ejercida por el pius Eneas (Aen. 4, 360, desine meque tuis incendere teque querelis; "con tus quejas deja de torturarme y torturarte"), va a resultar ejemplar. Recordemos que el episodio se convierte siglos después en la tragedia The Tragedie of Dido Queene of Carthage (publ. 1594) de Christopher Marlowe y quizá Thomas Nash, en la que la dureza del hexámetro virgiliano se transforma en un verso cortés que vale de hecho como estribillo -"Then let me go and never say farewell” (Act. 5, esc, 1, v. 124)-, para poco después incorporarse completo, no en inglés sino en el latín original (v. 139).

En suma, todos los capítulos invitan a la reflexión en torno a muchos textos dramáticos, que se ofrecen, ordenan y analizan para una renovada lectura que requiere otra mirada y más claves sobre una cuestión crucial. De hecho, este pequeño volumen es tan estimulante que plantea cuestiones que esperamos puedan ser tratadas pronto en un segundo, como, entre otras, la función de las mujeres violentas en escena, el efecto sin duda diverso en el auditorio, la influencia de estos modelos de comportamiento y de expresión en los autores posteriores y la censura (o no) en sus representaciones públicas a lo largo de los siglos. 